\title{
Estrogen alters thresholds for $B$ cell apoptosis and activation
}

\author{
Christine M. Grimaldi, ${ }^{1}$ James Cleary, ${ }^{1}$ A. Selma Dagtas, ${ }^{1}$ Dariush Moussai, ${ }^{1}$ \\ and Betty Diamond ${ }^{1,2}$ \\ ${ }^{1}$ Department of Microbiology and Immunology, and \\ ${ }^{2}$ Department of Medicine, Albert Einstein College of Medicine, Bronx, New York, USA \\ Address correspondence to: Betty Diamond, Department of Microbiology and Immunology, \\ 1300 Morris Park Avenue, Room 405, Forchheimer Building, Bronx, New York 10461, USA. \\ Phone: (718) 430-4081; Fax: (718) 430-8711; E-mail: diamond@aecom.yu.edu. \\ Christine M. Grimaldi and James Cleary contributed equally to this work.
}

Received for publication December 17, 2001, and accepted in revised form May 14, 2002.

Estrogen is thought to contribute to the increased frequency of autoimmune disorders occurring in females, but a molecular basis for its effects on autoimmunity remains to be elucidated. We have shown previously that estrogen leads to the survival and activation of autoreactive cells in the naive repertoire. To identify the molecular pathways involved in B cell tolerance, we sought to identify genes that are differentially regulated by estrogen in mouse B cells. Several genes involved in B cell activation and survival, including $c d 22, s h p-1, b c l-2$, and $v c a m-1$, were upregulated by estrogen in B cells. We found that overexpression of CD22 and SHP-1 in B cells decreased B cell receptor signaling. Estrogen receptors $\alpha$ and $\beta$ are expressed on $B$ cells and are functional, since they can directly upregulate expression of CD22, SHP-1, and Bcl-2. Estrogen treatment protected isolated primary B cells from B cell receptor-mediated apoptosis. These results suggest that estrogen induces a genetic program that alters survival and activation of B cells in a B cell-autonomous fashion and thus skews the naive immune system toward autoreactivity.

J. Clin. Invest. 109:1625-1633 (2002). doi:10.1172/JCI200214873.

\section{Introduction}

It has become apparent over the past few decades that estrogen can affect cells of the immune system and may play a role in modulating lymphocyte development and function (1-3). Of particular importance is the association between estrogen and the increased incidence of autoimmune disorders in women, such as systemic lupus erythematosus (SLE), which occurs at a femaleto-male ratio of 10:1 (4-6). Abnormal estrogen metabolism has been reported in patients with $\operatorname{SLE}(7,8)$, and there are indications that modulation of sex hormone levels may have clinical benefits (9).

Several studies have shown that estradiol $\left(\mathrm{E}_{2}\right)$ treatment accelerates the onset of disease and increases mortality in autoimmune-prone NZB/NZW $F_{1}$ and MRL/lpr mouse strains (10-12). Similarly, an elevation in serum autoantibody titers has been observed in $\mathrm{E}_{2}$-treated nonautoimmune $\mathrm{C} 57 \mathrm{BL} / 6$ mice (13). We have shown previously that $\mathrm{E}_{2}$ treatment of nonautoimmune $\mathrm{BALB} / \mathrm{c}$ mice transgenic for the $\gamma 2 \mathrm{~b}$ heavy chain of the R4A anti-double stranded DNA Ab perturbs tolerance induction of high-affinity autoreactive $B$ cells $(14,15)$. Examination of $E_{2}$-treated R4A- $\gamma 2 b$ $\mathrm{BALB} / \mathrm{c}$ mice revealed that a population of naive antiDNA B cells is rescued that would normally be deleted at an immature stage of $B$ cell development. Anti-DNA $B$ cells of $E_{2}$-treated mice develop preferentially into marginal zone $B$ cells, suggesting that $\mathrm{E}_{2}$ augments the generation of marginal zone B cells or, alternatively, that their antigenic specificity determines their localization to the marginal zone compartment (16).

The purpose of this study was to understand the skewing of the naive $B$ cell repertoire by estrogen by identifying alterations in gene expression in B cells exposed to a sustained concentration of $\mathrm{E}_{2}$ of approximately $75 \mathrm{pg} / \mathrm{ml}$. Furthermore, we sought to determine if activated estrogen receptors (ERs) in B cells lead to the upregulation of those genes and cause alterations in B cell function. Subtractive hybridization and screening of cDNA array filters were performed, and $c d 22, s h p-1, b c l-2$, and $v c a m-1$ were chosen for further study. These proteins are upregulated in B cells of $\mathrm{E}_{2}$-treated mice. We have further established that both known ERs are expressed in B cells and that expression of activated ERs in B cells can lead to upregulation of these genes with consequent alterations in B cell function. Taken together, these data suggest that an elevation in $\mathrm{E}_{2}$ leads directly to molecular changes in $\mathrm{B}$ cells that alter survival of immature $B$ cells and generates a peripheral B cell repertoire that includes autoreactive B cells that would normally be deleted.

\section{Methods}

$E_{2}$ treatment of mice. BALB/c mice (2-3 months old) were purchased from The Jackson Laboratories (Bar Harbor, Maine, USA), and transgenic R4A- $\gamma 2 \mathrm{~b}$ BALB/c mice 
(2-3 months old) were bred in a specific pathogen-free barrier facility. Mice were treated with $17 \beta$-estradiol $\left(\mathrm{E}_{2}\right)$ 60-day time-release pellets containing $0.18 \mathrm{mg}$ of $\mathrm{E}_{2}$ or with placebo $(\mathrm{P})$ pellets (Innovative Research of America, Saratoga, Florida, USA) for 3-6 weeks as previously described (14). In some experiments, mice were ovariectomized prior to $\mathrm{E}_{2}$ treatment.

Subtractive hybridization with PCR suppression. $\mathrm{B} 220^{+}$ splenic B cells were isolated using anti-B220 magnetic beads (Miltenyi Biotec, Auburn, California, USA) according to the manufacturer's protocol. B cell purity was typically $80-90 \%$ and devoid of T cells as determined by flow cytometry. Total RNA was prepared using guanidinium isothiocyanate (17), and subtractive hybridization with PCR suppression (SSH-PCR) was performed using the PCR-Select cDNA Subtraction Kit (CLONTECH Laboratories Inc., Palo Alto, California, USA) according to the manufacturer's protocol. Forward and reverse subtractions were performed, and the resulting PCR products were cloned into the TA PCR cloning vector (Invitrogen Corp., Carlsbad, California, USA). Nucleotide sequences were determined and analyzed using the BLAST program. Selected clones were analyzed by "virtual" Northern blot hybridization (18) or by semiquantitative RT-PCR. Scanning densitometry was performed using a Molecular Dynamics scanning densitometer (Sunnyvale, California, USA) and ImageQuant NT version 5.0 software. The signal intensities were normalized to gapdh. Screening of cDNA expression arrays. The Atlas mouse cDNA expression array (CLONTECH Laboratories Inc.) containing 588 known murine genes was screened. Splenic B cells were isolated from three $\mathrm{E}_{2}$ - or P-treated R4A- $\gamma 2 \mathrm{~b}$ mice as described above, and total RNA (2.0 $\mu \mathrm{g})$ was pooled and used to generate ${ }^{32} \mathrm{P}$-radiolabeled cDNA probes according to the manufacturer's protocol. Hybridization signals were normalized to gapdh.

RT-PCR analysis of vcam-1. To confirm the presence of vcam-1 mRNA in B cells, RT-PCR was performed using total RNA extracted from $\mathrm{B} 220^{+}$, CD5- sorted murine $B$ cells. PCR primers were generated that amplify exons 9 (sense, GCTCACAATTAAGAAGTTTAA) and 10 (antisense, TGCTGCTACTCTAAACAACCTC) and flank the transmembrane and cytoplasmic domains, respectively. Relative levels of vcam-1 mRNA were determined by semiquantitative RT-PCR using Quantum RNA 18S Internal Standards (Ambion Inc., Austin, Texas, USA) according to the manufacturer's protocol. RT-PCR was performed using primers that amplify an approximately 270-bp vcam-1 fragment of exon 10 (sense, AAACCAAGCCATGCATTCAGAC and the exon 10 antisense primer used above) plus the appropriate ratio of $18 S$ rRNA primer to $18 \mathrm{~S}$ rRNA competimer. The PCR products were separated on an ethidium-stained agarose gel and quantitated by scanning densitometry. Flow cytometry. Flow cytometry was performed with a FACScalibur flow cytometer (Becton-Dickinson Immunocytometry Systems, San Jose, California, USA), and analysis was performed using FlowJo software
(Tree Star Software, San Carlos, California, USA). Ab's to the following surface markers were used to identify $B$ cell subsets of bone marrow cells and splenocytes: CD19 (clone 6D5), CD21 (clone 7G6), CD1 (clone 1B1), B220 (clone RA3-6B2), CD24 (clone M1/69), T and $B$ cell activation antigen (clone GL7), and IgM (clone R6-60.2). All Ab's were purchased from PharMingen (San Jose, California, USA) except CD19 (Caltag Laboratories Inc., Burlingame, California, USA). VCAM-1 was measured with biotinylated anti-VCAM-1 (clone 429; PharMingen) and RPE-Neutravidin (Molecular Probes Inc., Eugene, Oregon, USA), and CD22 was measured with anti-CD22 (clone Cy34.1; PharMingen).

Intracellular staining was performed as described by Merino et al. (19). Cells were incubated with rabbit anti-Bcl-2, rabbit anti-SHP-1, and anti-ER- $\alpha$ (all purchased from Santa Cruz Biotechnology Inc., Santa Cruz, California, USA) or anti-ER- $\beta$ (Affinity BioReagents Inc., Boulder, Colorado, USA) or rabbit IgG as an isotype control diluted in $0.3 \%$ saponin (SigmaAldrich, St. Louis, Missouri, USA), followed by FITClabeled anti-rabbit IgG (PharMingen).

Transfection of murine $B$ cell lines with cDNA constructs. Constructs expressing wild-type ER- $\alpha$ (generously provided by Pierre Chambon, Institut de Genetique et de Biologie Moleculaire et Cellulaire, College de France, Strasbourg, France), constitutively active ER- $\alpha$ cDNA (generously provided by Benita Katzenellenbogen, University of Illinois at Urbana-Champaign, Urbana, Illinois, USA), and CD22 and SHP-1 (both generously provided by Mark S. Schlissel, University of California Berkley, Berkley, California, USA) were transiently transfected into murine B cell lines by electroporation (BioRad Laboratories Inc., Hercules, California, USA). To determine transfection efficiency, a plasmid encoding truncated human CD4 (pMACS 4.1; Miltenyi Biotec) was used. Briefly, $300 \mu$ of cells $\left(2 \times 10^{7}\right.$ cells $\left./ \mathrm{ml}\right)$ were suspended in RPMI medium and incubated with the plasmid $(20 \mu \mathrm{g})$ plus carrier DNA $(200 \mu \mathrm{g}$ of salmon sperm DNA) for 10 minutes on ice before transfection. Calcium influx studies. Surface $\operatorname{IgM}^{+} \mathrm{K} 46 \mu$ lymphoma cells (generously provided by John Cambier, National Jewish Hospital, Denver, Colorado, USA) were transfected with $c d 22$ and shp-1 constructs. Forty-eight hours after transfection, cells were loaded with Indo-1 AM ester ( $5 \mu \mathrm{g} / \mathrm{ml}$; Molecular Probes Inc.). After baseline levels were determined, cells were treated with $2.5-20.0 \mu \mathrm{g} / \mathrm{ml}$ of anti-IgM F $\left(\mathrm{ab}^{\prime}\right)_{2}$ (Southern Biotechnology Associates, Birmingham, Alabama, USA), and calcium influx was measured using a FACSvantage (Becton Dickinson Immunocytometry Systems) and analyzed with FlowJo software.

Apoptosis assay. Splenocytes were isolated from $\mathrm{E}_{2-}$ and P-treated ovariectomized BALB $/ \mathrm{c}$ mice, and cells $\left(5 \times 10^{5} / 300 \mu \mathrm{l}\right)$ were cultured in Iscove's modified Dulbecco's medium (IMDM) with 5\% FCS for 30 minutes in the presence or absence of $30 \mu \mathrm{g} / \mathrm{ml}$ biotinlabeled anti-IgM (Southern Biotechnology Associates), 

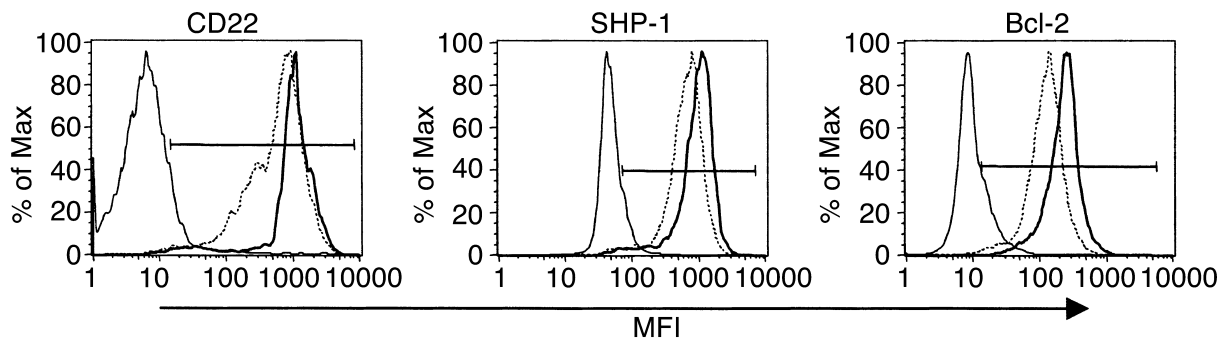

\section{Figure 1}

Expression profile of $\mathrm{E}_{2}$-regulated molecules in B cells. Mean fluorescence intensity of CD22, SHP-1, and Bcl-2 was determined by flow cytometry. Representative histograms of CD19-gated events are shown. The marker depicts positive staining above the isotype-matched control. A broken line represents the profile for the P-treated mouse, a solid line represents the profile for the $E_{2}$-treated mouse, and a thin solid line represents the isotype-matched control.

followed by the addition of $60 \mu \mathrm{g} / \mathrm{ml}$ Neutravidin (Southern Biotechnology Associates) for 12-18 hours. The percentage of cells undergoing apoptosis was determined by measuring levels of activated caspase 3 by flow cytometry. Cells were stained for B220 and CD24 and activated caspase 3-specific rabbit (clone C92-605; PharMingen) Ab's, followed by FITC-labeled anti-rabbit $\mathrm{Ab}$.

To determine the impact of $\mathrm{E}_{2}$ directly on $\mathrm{B}$ cell apoptosis, splenic B cells were isolated from ovariectomized mice by depletion using biotin-labeled antiCD43 (clone S7; PharMingen), anti-CD11c (clone HL3; Pharmingen), anti-CD90 (clone CT-TH1; Caltag Laboratories Inc.), and streptavidin-labeled Dynabeads (Dynal, Oslo, Norway). B cells were cultured in $\mathrm{E}_{2}$-free medium (IMDM without phenol red, $10 \%$ charcoal-filtered FCS) and pretreated for 5 hours with $\mathrm{E}_{2}\left(10^{-8} \mathrm{M}\right.$; Sigma-Aldrich) or with the $\mathrm{E}_{2}$ antagonist ICI $182,780\left(10^{-7} \mathrm{M}\right.$; Tocris Cookson Inc., Ballwin, Missouri, USA) as a negative control. Levels of activated caspase 3 were measured.

Statistical analysis. A Student two-tailed $t$ test was performed. A $P$ value of less than 0.05 was considered significant.

\section{Results}

Identification of $E_{2}$-regulated genes in $B$ cells. We have shown previously that a sustained increase in serum $\mathrm{E}_{2}$ to concentrations of $75 \mathrm{pg} / \mathrm{ml}$ is sufficient to abrogate tolerance induction, leading to the rescue and activation of a population of autoreactive $\mathrm{B}$ cells in $\mathrm{BALB} / \mathrm{c}$ mice that would normally be deleted (14-16). To identify genes that are differentially regulated in $\mathrm{B}$ cells of $\mathrm{E}_{2}$-treated mice, SSH-PCR and screening of cDNA array filters were performed. RNA derived from $\mathrm{B} 220^{+}$ splenic cells from a single $\mathrm{E}_{2}$-and a single $\mathrm{P}$-treated R4A- $\gamma 2$ b BALB/c mouse was used for SSH-PCR. Over 100 clones were sequenced, and candidate genes were analyzed by semiquantitative RT-PCR or by "virtual" Northern blot (data not shown) (18). In addition, a commercially prepared cDNA array filter containing 588 known mouse genes was screened using probes generated from $B$ cell RNA pooled from three $\mathrm{E}_{2^{-}}$or P-treated R4A- $\gamma 2 \mathrm{~b}$ BALB/c mice. Hybridization signals were normalized to gapdh.

Four of the genes, $c d 22$, shp- $1, b c l-2$, and $v c a m-1$ identified in the screens were known to play a role in B cell survival and activation (19-23) and were chosen for further study. In addition, $c d 22$ is located within the sle 3 susceptibility locus (24).

Examination of expression profile of $E_{2}$-regulated genes. Protein expression of CD22, SHP-1, Bc1-2, and VCAM-1 in $B$ cells was measured by flow cytometry. For these experiments, BALB/c mice that had been ovariectomized before initiation of $E_{2}$ or $P$ administration were examined to avoid the variability in gene expression levels that may occur in P-treated mice from changes in endogenous $E_{2}$ levels that occur at different phases of the estrus cycle. Expression levels were examined in nontransgenic $\mathrm{BALB} / \mathrm{c}$ mice to avoid alterations in B cell development that can be associated with immunoglobulin transgenes.

The CD22 receptor and the intracellular tyrosine phosphatase SHP-1 are molecules that regulate the threshold for B cell activation, while Bcl-2 plays an important role

Table 1

Expression levels of target genes in splenic B cells

\begin{tabular}{|c|c|c|c|c|c|}
\hline & $P$ & $E_{2}$ & $n^{\mathrm{A}}$ & $P$ value & Fold increase \\
\hline $\mathrm{CD} 22^{\mathrm{B}}$ & $959.8( \pm 413.2)$ & $1,285.7( \pm 461.0)$ & 12 & $<0.0008$ & 1.4 \\
\hline SHP-1 ${ }^{B}$ & $1,784.8( \pm 560.7)$ & $2,089.4( \pm 485.4)$ & 17 & $<0.04$ & 1.2 \\
\hline $\mathrm{Bcl}-2^{\mathrm{B}}$ & $175.8( \pm 25.9)$ & $215.1( \pm 61.1)$ & 17 & $<0.05$ & 1.2 \\
\hline VCAM-1 ${ }^{B}$ & $132.9( \pm 17.8)$ & $182.5( \pm 23.2)$ & 12 & $<0.0003$ & 1.4 \\
\hline
\end{tabular}

ANumber of $\mathrm{E}_{2}$ - and P-treated BALB/c mice analyzed. ${ }^{\mathrm{B} T h e}$ mean fluorescence intensities (MFIs) include only the portion of the histograms that are greater than the staining of isotype-matched controls. Data are represented as the MFI \pm SD of total CD19-gated events. Statistical significance was determined by a two-tailed paired Student $t$ test from data collected from two or more experiments. 
a
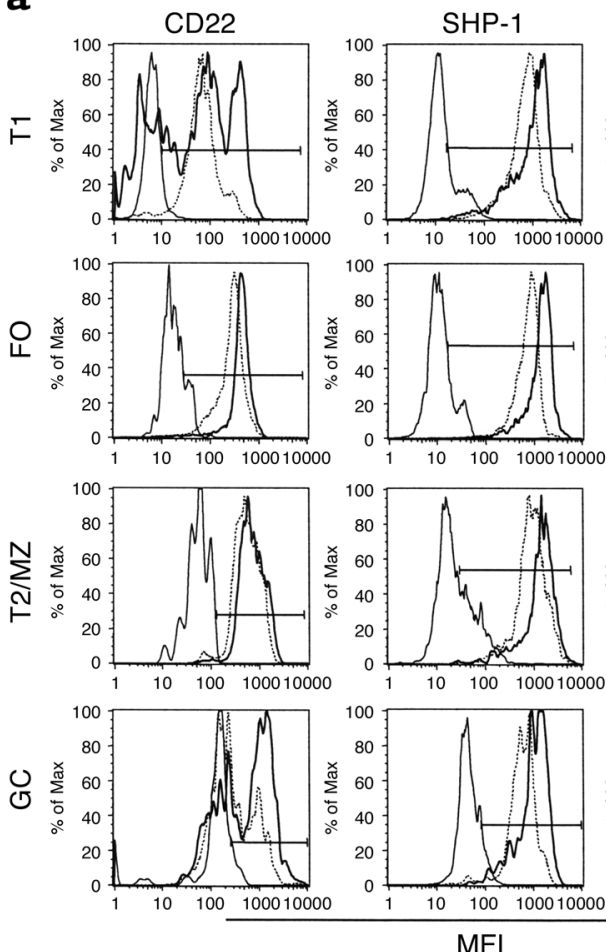
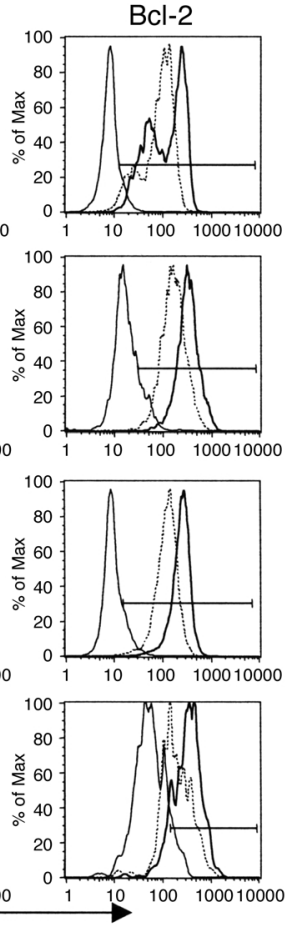

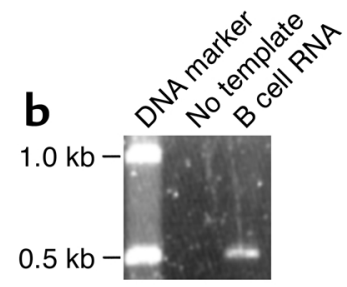

c
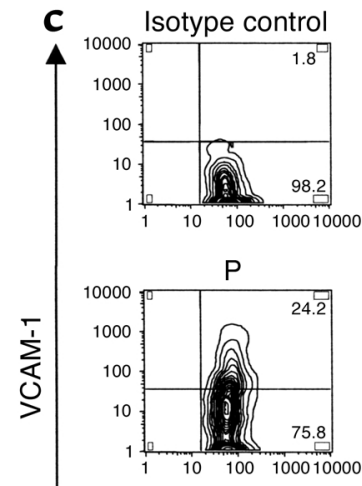

E2

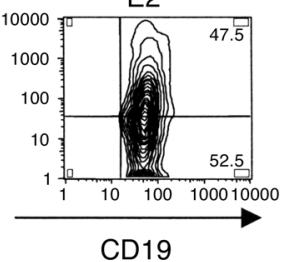

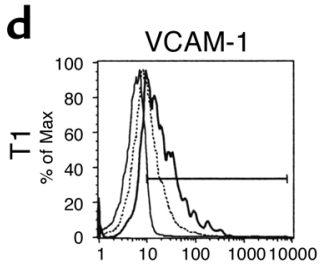
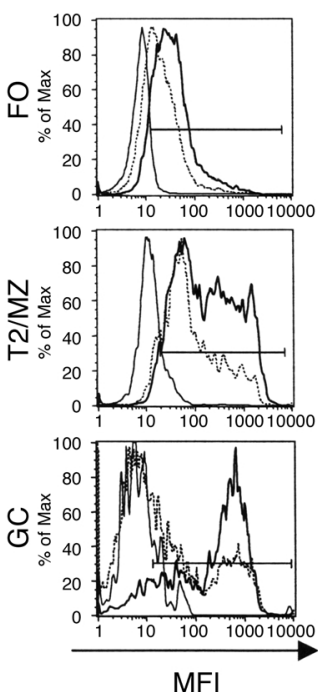

\section{Figure 2}

(a) Analysis of CD22, SHP-1, and Bcl-2 B cell subsets. Splenocytes from $\mathrm{E}_{2}$-treated (bold line) and P-treated (dashed line) mice $(n=5-10$ per group) were analyzed by flow cytometry using Ab's that recognize CD19 and B cell stage subset-specific markers. Representative histograms are shown, and the isotype-matched controls are represented by a thin solid line. Levels of CD21 or CD1 were used to distinguish between transitional T1 (T1; CD21 lo $/$ CD1 1o $)$, follicular (FO; CD21 int $/ C D 1^{\text {int }}$ ), and transitional T2 plus marginal zone (T2/MZ; CD21 hi/CD1 hi) B cell populations, and GL7 was used to identify germinal center (GC; GL7 $\left.{ }^{+}\right) \mathrm{B}$ cells. The marker depicts positive staining above the isotype-matched control. (b) Analysis of VCAM-1 in B cells. RT-PCR was performed on RNA extracted from sorted B220 ${ }^{+}$, CD5 $5^{-}$B cells, and the predicted 500-bp product for vcam-1 is shown. (c) A representative contour plot of CD19-gated events demonstrating expansion of VCAM-1+ $B$ cells in the spleens is shown. (d) Representative histograms of stage-specific expression of VCAM-1 in $E_{2}$-treated (bold line) and P-treated (dashed line) mice $(n=5)$ are shown, and values are presented in Table 1. The isotype-matched controls are represented by a thin solid line.

in B cell survival. Expression levels of these molecules were significantly increased in total splenic B cells (Figure 1 and Table 1). Previously, we have shown that $\mathrm{E}_{2}$ treatment alters the distribution of $\mathrm{B}$ cell subsets, leading to a decrease in transitional $\mathrm{B}$ cells and an increase in marginal zone B cells (16). Since expression levels of CD22, SHP-1, and Bcl-2 are known to vary among different B cell populations, levels of CD22, SHP-1, and $\mathrm{Bcl}-2$ were measured in immature transitional, marginal zone, follicular, and germinal center B cells separately using subset-specific gates. Examination of individual B cell subsets revealed increased expression of $\mathrm{CD} 22$, SHP-1, and Bcl-2 (Figure 2a). Since Bcl-2 regulates B cell survival at several stages of $B$ cell development $(19,22)$, $\mathrm{Bcl}-2$ expression was also examined in pro/pre $\mathrm{B}$ and immature bone marrow $B$ cell subsets. There was a significant increase in the percentage of $\mathrm{Bcl}-2^{+}$pro/pre $\mathrm{B}$ and immature $B$ cells in $E_{2}$-treated mice (Table 2). These results suggest that $E_{2}$ increases expression of key immunoregulatory molecules in B cells. Most notably, levels were increased at the transitional $\mathrm{T} 1$ and germinal center stages of B cell development, stages in which negative selection of autoreactive $B$ cells must occur to maintain normal B cell tolerance.

VCAM-1 has not been reported to be expressed in murine $B$ cells, but there is evidence that it is expressed in human B and T cells $(25,26)$. VCAM- 1 expression was detected by flow cytometry on normal CD $19^{+} \mathrm{B}$

\section{Table 2}

$\mathrm{Bcl}-2$ expression in bone marrow $\mathrm{B}$ cells of $\mathrm{BALB} / \mathrm{c}$ mice

P $\quad \mathrm{E}_{2} \quad P$ value Fold increase

Pro/Pre B cells

$\begin{array}{lllll}\mathrm{Bcl}-2(\%) & 21.9( \pm 9.2) & 40.8( \pm 4.4) & <0.004 & 1.9\end{array}$

Immature B cells

Bcl-2 (\%) $25.9( \pm 11.0) \quad 55.2( \pm 6.8) \quad<0.001$

Analysis of $\mathrm{E}_{2-}$ and P-treated BALB/c mice $(n=5)$ was performed on CD19gated events, and data are presented as the mean \pm SD of the percentage of $\mathrm{Bcl}-2^{+} \mathrm{B}$ cells. Statistical significance was determined by a two-tailed unpaired Student $t$ test. 


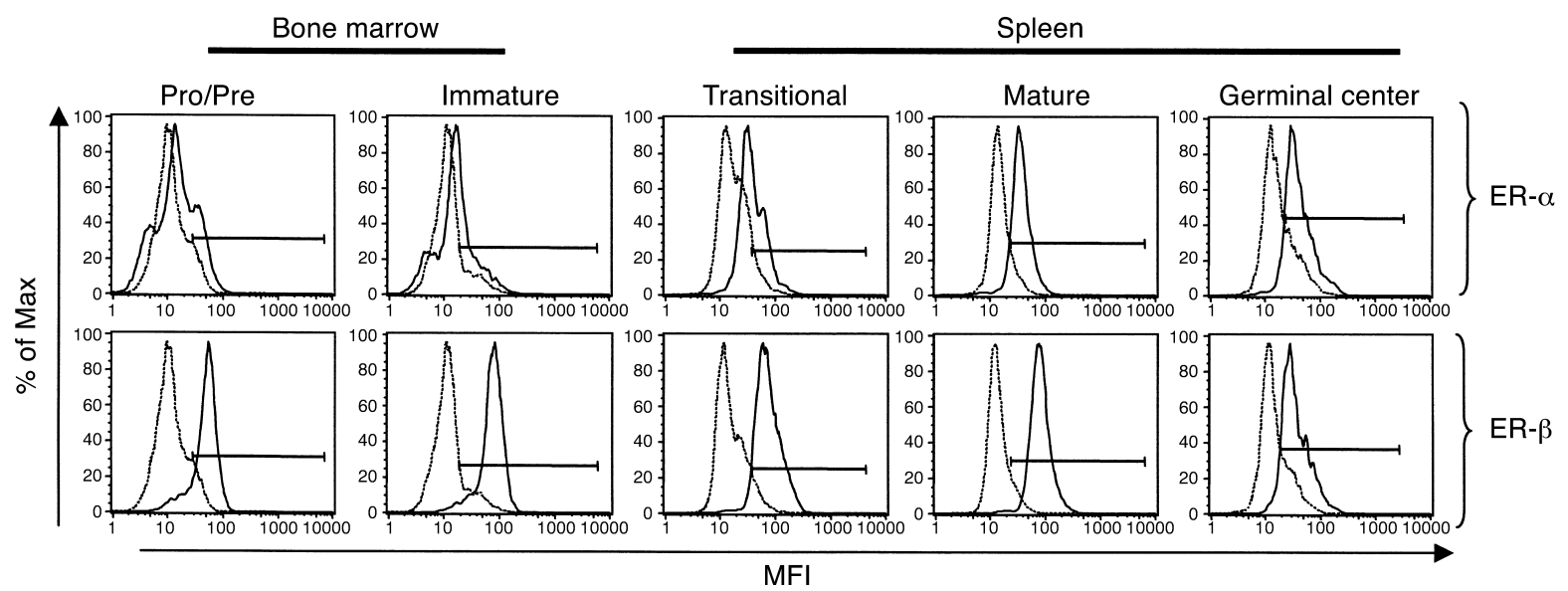

\section{Figure 3}

Detection of ERs in B cell subsets. Bone marrow cells and splenocytes were isolated, and cell suspensions from three mice were pooled together and stained with Ab's to detect ER- $\alpha$ or ER- $\beta$ plus Ab's to detect developmental surface markers. Bone marrow pro/pre cells were identified as B220 $\mathrm{lo} / \mathrm{slgM}^{-}$and immature as B220 $\mathrm{lo} / \mathrm{slgM}^{-}$. Splenic transitional B cells were identified as B220 ${ }^{\mathrm{lo}} / \mathrm{CD}^{2} 4^{\mathrm{hi}}$, mature as B220 int $/ \mathrm{CD}^{2} 4^{\mathrm{lo}}$, and germinal center as $\mathrm{CD} 19^{+} / \mathrm{GL7}^{+}$. The experiment was performed three times on a total of 13 mice, and representative histograms of stagespecific expression are shown. Specific staining is represented by a solid line, and the isotype-matched control is represented by a dashed line.

cells and on the S194 plasma B cell line (data not shown). To confirm that vcam-1 mRNA is present in B cells, RT-PCR was performed using RNA from cellsorted $\mathrm{B} 220^{+} / \mathrm{CD}^{-}$splenic $\mathrm{B}$ cells with primers that span exons 9 and 10 of the transmembrane and cytoplasmic domains of $v$ cam-1. The resulting vcam-1 PCR product was the appropriate $500 \mathrm{bp}$; therefore, it was derived from mRNA and not contaminating genomic DNA (Figure 2b). Semiquantitative RT-PCR demonstrated that the vcam-1 transcript is increased approximately 2.5 -fold in $\mathrm{B}$ cells of $\mathrm{E}_{2}$-treated mice (data not shown). A significant increase in the number of VCAM- $1^{+}$B cells (Figure $2 \mathrm{c}$ ) and expression levels of VCAM-1 (Table 2) were observed in $\mathrm{E}_{2}$-treated mice. In addition, expression levels of VCAM-1 were increased in all $B$ cell subsets examined (Figure $2 d$ ).

These data demonstrate that $\mathrm{E}_{2}$ treatment alters the expression pattern of CD22, SHP-1, Bcl-2, and VCAM1 in $B$ cells. These increases are specific, because the expression of common B cell markers, such as B220, CD24, CD23, CD1, and CD 44, were unaffected by $E_{2}$ treatment (data not shown).

ER- $\alpha$ and ER- $\beta$ expression in $B$ cells. We were interested in determining if murine $\mathrm{B}$ cells are directly $\mathrm{E}_{2}$ responsive. Cells of the immune system, such as stromal cells, T cells, and dendritic cells, express functional ERs (1,27-29). There is also evidence for the presence of ER mRNA and protein in B cells (30-33); however, it is not known if these receptors function as transcriptional activators in these cells. We sought first to determine when ER- $\alpha$ and $-\beta$ are present in murine B cells.

By intracellular flow cytometry, ER- $\beta$ expression was observed at all stages of B cell development (Figure 3). Low to negligible levels of ER- $\alpha$ were detected in pro/pre B cells (B220 ${ }^{\text {lo }}$, surface $\left.\operatorname{IgM}^{-}\left[\mathrm{sIgM}^{-}\right]\right)$and immature B cells $\left(B 220^{\mathrm{lo}}, \mathrm{sIgM}^{+}\right)$of the bone marrow; ER- $\alpha$ was clearly present in transitional $\mathrm{B}$ cells $\left(\mathrm{B} 220^{\mathrm{lo}}, \mathrm{CD} 24^{\mathrm{hi}}\right)$, mature
B cells (B220 int, CD24 $4^{\text {lo }}$, and germinal center B cells $\left(\mathrm{CD}_{19}{ }^{+}, \mathrm{GL}^{+}\right)$of the spleen (Figure 3 ). This developmentally regulated increase in ER- $\alpha$ has been seen in other cell lineages also (34). In agreement with the flowcytometry data, RT-PCR using ER- $\alpha$ - and ER- $\beta$-specific primers demonstrated the presence of ER- $\alpha$ and ER- $\beta$ transcripts in B cell lines representing immature and mature stages of B cell development (data not shown). Induction of $E_{2}$-regulated genes by ectopic expression of activated ERs. To determine whether $c d 22$, shp-1, and $b c l-2$ can be directly induced by activated ERs in B cells, B cell lines were transiently transfected with a cDNA construct that expresses the constitutively active ER- $\alpha$. In the $18-81$ pre$B$ cell line, ectopic expression of active ER- $\alpha$ resulted in upregulation of SHP-1 and Bcl-2. The A20 mature B cell line displayed increased expression of CD22, SHP-1, and Bcl-2 (Table 3). Finally, the S194 plasma cell line

\section{Table 3}

Expression profile of target genes in B cell lines transfected with constitutively active ER- $\alpha$

$\begin{array}{lll}\text { Mock } & \text { ER- } \alpha \quad P \text { value Fold increase }\end{array}$

18-81 cells

$\begin{array}{lllll}\text { SHP-1 } & 88.4( \pm 4.6) & 186.7( \pm 42.2) & <0.02 & 2.1 \\ \text { Bcl-2 } & 71.0( \pm 15.4) & 112.3( \pm 14.6) & <0.03 & 1.6\end{array}$

A20 cells

SHP-1 $335.6( \pm 49.1) \quad 1,021.4( \pm 35.6)<0.00005 \quad 3.0$

$\begin{array}{lllll}\mathrm{BCl}-2 & 112.3( \pm 1.4) & 187.4( \pm 12.0) & <0.0004 & 1.7\end{array}$

$\begin{array}{lllll}\text { CD22 } & 30.4( \pm 0.5) & 41.7( \pm 1.7) & <0.0009 & 1.4\end{array}$

S194 cells

SHP-1 $838.2( \pm 25.6) \quad 1,097.1( \pm 26.9) \quad<0.0003 \quad 1.3$

Bcl-2 $57.2( \pm 1.2) \quad 66.7( \pm 2.7) \quad<0.005 \quad 1.2$

Data for SHP-1, Bcl-2, and CD22 are presented as the mean \pm SD of the MFI. The MFIs include only the portion of the histograms that are greater than the staining of isotype-matched controls. Statistical significance was determined by a two-tailed unpaired Student $t$ test of triplicate samples. 
a
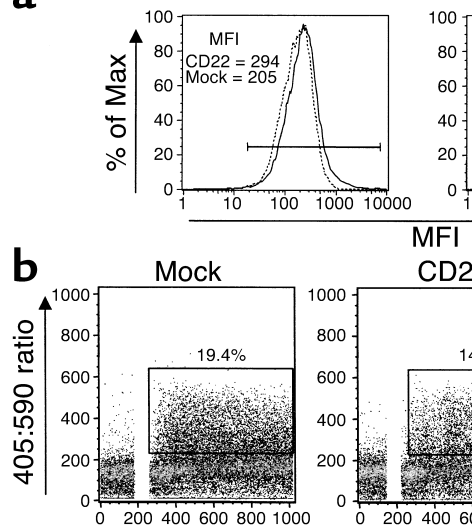

CD22

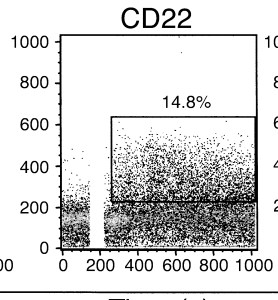

Time (s)

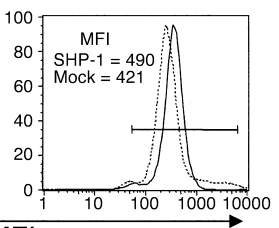

SHP-1

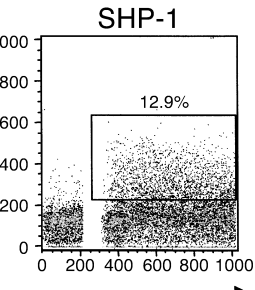

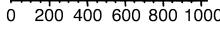

displayed increased expression of SHP-1 and Bcl-2. These data demonstrate that ER activation in B cells directly induces expression of these target genes.

Alterations in B cell receptor-mediated signals in CD22-and SHP-1-transfected cells. It is well described that CD22 and SHP-1 both help regulate strength of B cell receptor (BCR) signaling. B cells of mice deficient in CD22 or SHP-1 display an augmented calcium response following surface Ig cross-linking $(21,35)$. We overexpressed CD22 or SHP-1 in the K46 $\mu$ B lymphoma cell line to simulate the increase seen in $\mathrm{B}$ cells of $\mathrm{E}_{2}$-treated mice. Thus, CD22- or SHP-1-transfected cells displayed a $19-25 \%$ increase in CD22 or SHP-1 compared with mock-transfected cells (Figure 4a). Following addition of anti-IgM $\mathrm{F}\left(\mathrm{ab}^{\prime}\right)_{2}$ to act as surrogate antigen, the

\section{Figure 5}

IgM-mediated apoptosis in $\mathrm{E}_{2}$-treated splenic B cells. Levels of activated caspase 3 were measured by flow cytometry to identify (a) $\mathrm{B} 220^{+} / \mathrm{CD} 24^{\text {hi }}$ (transitional) and (b) B220 $/$ CD $24^{\text {lo }}$ (mature) cells undergoing apoptosis. Representative histograms of splenocytes from $\mathrm{P}$ - and $\mathrm{E}_{2}$-treated mice incubated with anti-lgM (solid line) or without anti-IgM (dashed line) are shown. For anti-IgM-treated splenocytes, 26,661 (P) and 12,075 ( $\left.E_{2}\right)$ transitional B cell-gated events and 139,416 (P) and 127,235 $\left(E_{2}\right)$ mature $B$ cell-gated events were examined, respectively. For untreated splenocytes, 20,912 (P) and 10,437 $\left(E_{2}\right)$ transitional $B$ cell-gated events and 57,600 $(P)$ and $64,489\left(E_{2}\right)$ mature $B$ cell-gated events were examined, respectively. The experiment was performed on B cells from five mice in each treatment group, and similar results were observed for all mice within a group. The percentage of transitional $B$ cells from $E_{2}$-treated mice undergoing apoptosis was significantly reduced $(P<0.02)$ compared with P-treated mice. There was no significant reduction in the percentage of mature B cells undergoing apoptosis. (c) Splenic B cells isolated from ovariectomized mice BALB/c mice $(n=5)$ were incubated with $E_{2}$ or the $E_{2}$ antagonist ICI 182,780 5 hours before the addition of anti-IgM. Representative histograms from one of three experiments are shown. For B cells incubated with anti-IgM plus $I C I$ 182,780, 2,382 lymphocyte-gated events were examined; for B cells incubated with anti-IgM plus $E_{2}, 4,161$ lymphocyte-gated events were examined; for B cells incubated with ICI 182,780 alone, 6,426 lymphocyte-gated events were examined; and for B cells incubated with $E_{2}$ alone, 7109 lymphocyte-gated events were examined. Anti-IgMinduced apoptosis was reduced in cells pretreated with $\mathrm{E}_{2}(P<0.05)$.

\section{Figure 4}

(a) Expression profiles of CD22- and SHP-1-transfected cells. Levels of CD22 and SHP-1 were determined by flow cytometry and histograms of mock (dashed line) and CD22- or SHP-1-transfected (solid line) cells are shown. CD22- and SHP-1-transfected cells display approximately a $20 \%$ increase in CD22 and SHP-1 levels. (b) Calcium influx in CD22- and SHP-1-transfected K46 $\mu$ cells. The $\mathrm{K} 46 \mu$ cell line was transfected with plasmids that express CD22 or SHP-1 and with one-tenth the concentration of a plasmid that expresses human CD4 to determine transfection efficiency. Fortyeight hours after transfection, cells were loaded with Indo-1 AM, and calcium influx was measured using $2.5-20 \mu \mathrm{g} / \mathrm{ml}$ of anti-lgM $\mathrm{F}\left(\mathrm{ab}^{\prime}\right)_{2}$. Representative dot plots depicting the percentage of cells responding to $10 \mu \mathrm{g} / \mathrm{ml}$ of anti-IgM $\mathrm{F}\left(\mathrm{ab}^{\prime}\right)_{2}$ are shown, and similar results were obtained for all doses examined. These experiments were repeated three times, and similar results were obtained.

CD22- and SHP-1-transfected populations exhibited a diminished calcium response compared with mocktransfected cells (Figure 4b). These results suggest that an increase of approximately $20 \%$ in either CD22 or SHP-1, similar to the upregulation seen in the B cells of $\mathrm{E}_{2}$-treated mice, can alter signals mediated through the $\mathrm{BCR}$. Thus, $\mathrm{E}_{2}$-induced expression of these molecules in $B$ cells may increase the antigen concentration required for the tolerization of autoreactive $B$ cells.

Impaired apoptosis of $E_{2}$-treated $B$ cells. $\mathrm{E}_{2}$ treatment perturbs negative selection of autoreactive $B$ cells $(14,16)$. To determine if the $\mathrm{B}$ cells from $\mathrm{E}_{2}$-treated mice display a defect in BCR-mediated apoptosis, splenocytes from $\mathrm{E}_{2}$ - and P-treated mice were isolated and treated in vitro with anti-IgM to simulate antigen-induced apoptosis.

a In vitro-treated immature transitional cells
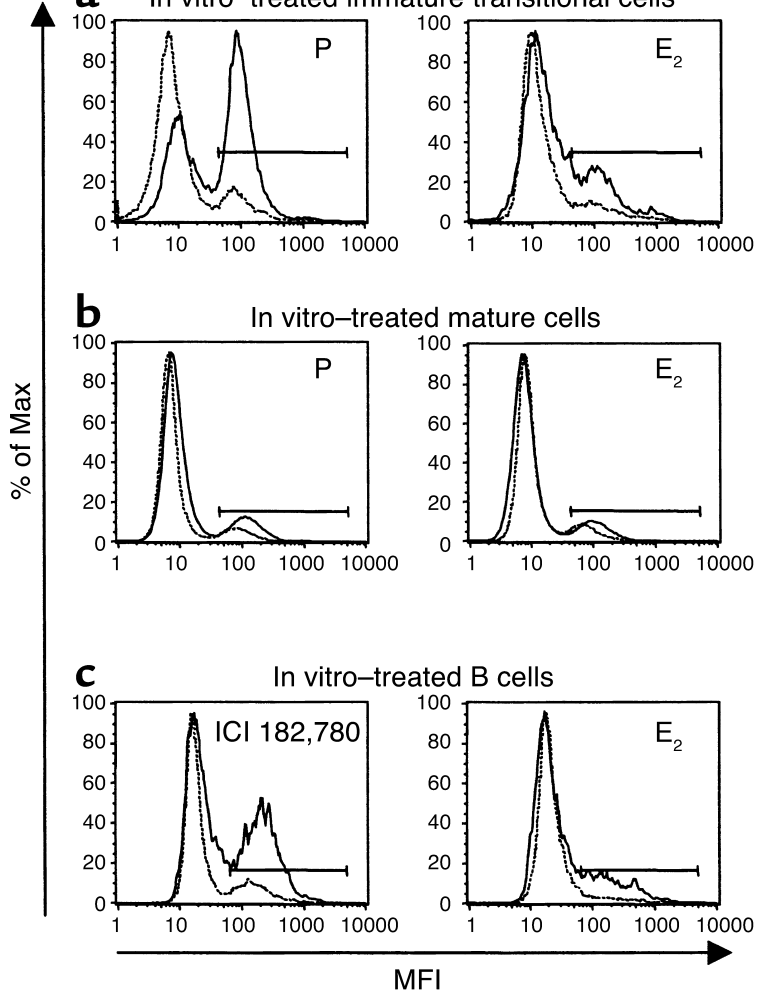
Cells were stained for the markers B220 and CD24 to distinguish immature transitional $\left(\mathrm{B} 220^{+}, \mathrm{CD} 24^{\mathrm{hi}}\right)$ and mature $\left(\mathrm{B} 220^{+}, \mathrm{CD} 24^{\mathrm{l}}\right) \mathrm{B}$ cells and with an $\mathrm{Ab}$ that is specific for the activated form of caspase 3 , since activation of caspase 3 is involved in BCR-mediated apoptosis $(36,37)$. Flow cytometry was performed to identify B cells undergoing apoptosis (Figures 5, a and b). B cell receptor-mediated apoptosis was significantly reduced in immature transitional B cells (CD24hi) from $\mathrm{E}_{2}$-treated mice (Figure 5a). This is in agreement with previous reports demonstrating that transitional $\mathrm{B}$ cells are more susceptible to anti-IgM-mediated apoptosis than mature B cells (38) and is consistent with the survival of naive $B$ cells demonstrated previously in $\mathrm{E}_{2}$-treated mice (16). The extent of anti-IgM-mediated apoptosis was much lower in the mature $\mathrm{B}$ cell population, and there was no significant rescue by $\mathrm{E}_{2}$.

We next wanted to determine if $\mathrm{E}_{2}$ can directly block apoptosis of B cells. Splenocytes from ovariectomized mice were isolated and treated with $E_{2}$ or the pure $E_{2}$ antagonist ICI 182,780 to inhibit estrogenic compounds in the culture system, followed by the addition of anti-IgM. $E_{2}$ treatment protected purified B cells from BCR-mediated apoptosis (Figure 5c). These data suggest that $\mathrm{E}_{2}$ can directly rescue $\mathrm{B}$ cells from signals that mediate negative selection.

\section{Discussion}

There is increasing evidence for a role for $\mathrm{E}_{2}$ in regulation of the immune system. A sustained increase in $\mathrm{E}_{2}$ has been linked to autoimmunity and may contribute to the increased frequency of SLE in females $(4,5)$. Our laboratory has shown previously that $E_{2}$ administration of R4A- $\gamma 2 \mathrm{~b}$ BALB/c mice that express an anti-DNA $A b$ heavy chain leads to the rescue of a population of naive autoreactive $B$ cells that would normally be deleted at an immature stage of B cell development $(14,15)$. In addition, the distribution of peripheral $\mathrm{B}$ cell subsets is altered in $\mathrm{E}_{2}$-treated mice, and the bulk of the autoreactive $B$ cell population are marginal zone $\mathrm{B}$ cells (16). $\mathrm{E}_{2}$ appears to favor the progression from the transitional $\mathrm{T} 2 \mathrm{~B}$ cell stage to marginal zone B cells (16). This developmental pathway may reflect impaired negative selection at the transitional B cell stage. Thus, we felt that the $\mathrm{E}_{2}$-induced model of autoreactivity would be useful to identify molecular pathways that can contribute to escape from self tolerance.

We have demonstrated that both known ERs are present in murine $B$ cells and that $E_{2}$ may exert a direct molecular effect on B cells. ER- $\alpha$ and ER- $\beta$ exhibit similar ligand binding and transactivation properties and can form functional heterodimers $(39,40)$. However, there is also evidence that ER- $\alpha$ and ER- $\beta$ may differentially regulate target gene expression based on the activation pattern of distinct estrogen response element reporter constructs (39) and on differential effects of ectopic expression of ER- $\alpha$ and ER- $\beta$ in SK-N-BE neuroblastoma cells (41). It remains to be determined which ERs mediate changes in gene expression at different developmental stages in $\mathrm{B}$ cells. Increased expression of $\mathrm{Bcl}-2$ is believed to be responsible for decreased apoptosis in the MCF-7 breast cancer cell line in the presence of $\mathrm{E}_{2}(42-44)$. We have demonstrated previously by immunohistochemistry that $\mathrm{Bcl}-2$ expression is increased in the spleens of $\mathrm{E}_{2}$-treated mice (14) and have confirmed this observation by flow cytometry. Overexpression of Bcl-2 in several transgenic mouse models enhances survival of autoreactive $\mathrm{B}$ cells that arise in the bone marrow (45-47) and of B cells that acquire autoreactivity following somatic mutation in germinal centers $(48,49)$. We observed an expansion of $\mathrm{Bcl}-2^{+} \mathrm{B}$ cell progenitors in the bone marrow of $\mathrm{E}_{2}$-treated mice. A similar expansion of bone marrow progenitor $\mathrm{B}$ cells in $\mathrm{E}_{2}$-treated mice has been reported by Medina and colleagues (50). The increased expression of Bcl-2 may protect B cell progenitors from BCR-mediated apoptosis and contribute to the survival of high-affinity anti-DNA B cells that are normally deleted at the immature stage of development. A sustained increase in Bcl-2 expression in splenic B cells may also enhance survival of autoreactive $B$ cells in the periphery and block negative selection in germinal centers. B cells at the immature and transitional stages are most susceptible to BCR-induced cell death (38). Consistent with this is the observation that $\mathrm{E}_{2}$ treatment of primary B cells impaired anti-IgM-mediated cell death of transitional $B$ cells. These data suggest that $E_{2}$ can alter negative selection in naive immature $B$ cells.

It is also likely that increased B cell expression of SHP-1 and CD22 promotes the presence of autoreactive $B$ cells in the mature B cell repertoire. Calcium influx studies suggest that an increase in expression of CD22 or SHP-1 decreases signaling through the BCR, in agreement with results observed in $\mathrm{K} 46 \mu$ cells transfected with CD72, another molecule known to downregulate signals mediated through the BCR (51). While mice deficient in SHP-1 or CD22 display increased autoantibody titers, the autoantibodies are produced by B-1 B cells and not by conventional B cells $(52,53)$. When SHP-1-deficient conventional B cells are autoreactive, they are more sensitive to programmed cell death and are deleted by low-valency antigen that does not delete SHP- $1^{+}$B cells (21). Thus, it appears that SHP-1 overexpression can favor survival of autoreactive B cells. CD22 has also been reported to be both a positive and negative regulator of B cell survival and activation (20). There are currently no transgenic mouse models for the overexpression of SHP-1 or CD22 in B cells to directly test the effect of their increased expression. However, since these molecules are involved in increasing the threshold for signaling through the BCR, it is likely that increased expression of these molecules would impair tolerization of either high-affinity autoreactive naive $B$ cells, causing them to behave as indifferent or ignorant $B$ cells, or antigen-activated germinal center B 
cells. Interestingly, a polymorphism of $c d 22$ associates with SLE in a study of Japanese patients (54).

The adhesion molecule VCAM- 1 was detected by both SSH-PCR and screening of array filters as a gene that is upregulated by $\mathrm{E}_{2}$ in $\mathrm{B}$ cells. We included VCAM- 1 in these studies despite the existence of only a few reports demonstrating the presence of VCAM- 1 in human B and $T$ cells $(25,26)$ and because previous studies showed increased VCAM-1 expression in SLE patients and in MRL/lpr mice $(55,56)$. We have determined that VCAM- 1 is present in normal murine B cells and also in murine $T$ cells (C.M. Grimaldi and B. Diamond, unpublished observation). VCAM-1 serves as a ligand for the integrin receptor VLA-4. Engagement of VLA-4 in B cells plays a role in early B cell development in the bone marrow (23) and protects B cells against apoptosis in germinal centers (57). It is possible that increased expression of VCAM-1 on B cells may help mediate B cell autonomous protection against apoptosis by providing the ligand for VLA-4. Since VLA-4 is expressed T cells, as well as B cells, another potential role for VCAM-1 on B cells may be to mediate B-T cell interactions that protect against apoptosis.

For all the proteins studied, $\mathrm{E}_{2}$ induces an increase in expression levels from $15 \%$ to $27 \%$. It is well described that these small changes in the level of expression of critical molecules can alter the function of the immune system. Sato and colleagues demonstrated that a $15-29 \%$ increase in CD19 expression in B cells was sufficient to induce the production of autoantibodies in C57BL/ 6 mice $(58,59)$. In a recent study, it was demonstrated that the peripheral blood B cells of patients with the autoimmune disorder systemic sclerosis exhibit a 20\% increase in CD19 expression and a 23\% increase in CD21 expression (58). Similarly, Bcl-2 expression needs to be increased by only $30 \%$ (C.M. Grimaldi and B. Diamond, unpublished observation) to lead to rescue of high-affinity anti-DNA $B$ cells in $\mathrm{R} 4 \mathrm{~A}-\gamma 2 \mathrm{~b} \mathrm{BALB} / \mathrm{c}$ mice that are also transgenic for $\mathrm{B}$ cell-specific expression of $b c l-2(60)$. Thus, it was reasonable to speculate that the changes in protein levels induced by $\mathrm{E}_{2}$ can alter the phenotype of the immune system. Our data on calcium influx in CD22- and SHP-1-transfected cells confirm that small increases in protein expression alter $\mathrm{B}$ cell function.

These studies have begun to decipher the molecular pathways activated by estrogen that lead to survival and activation of naive autoreactive $B$ cells. The data demonstrate a direct effect of $\mathrm{E}_{2}$ on $\mathrm{B}$ cells and begin to describe the gene expression program initiated in $\mathrm{B}$ cells of $\mathrm{E}_{2}$-treated mice. Continued studies will not only unravel the impact of sex hormones on B cell biology, but will help identify pathways important in the regulation of autoreactive $B$ cells that are dysregulated by $E_{2}$ or other triggers. These studies will permit us to determine if $\mathrm{E}_{2}$ contributes to disease expression in a cohort of autoimmune patients or if there are other genetic or environmental factors that lead to activation of $\mathrm{E}_{2}$-inducible pathways in patients with SLE or other immune diseases.

\section{Acknowledgments}

This work was supported by grants from the NIH (to B. Diamond) and the New York Chapter of the Arthritis Foundation (to C.M. Grimaldi). J. Cleary is funded by NIH Medical Scientist Training Program grant T32-GM07288.

1. Smithson, G., Couse, J.F., Lubahn, D.B., Korach, K.S., and Kincade, P.W 1998. The role of estrogen receptors and androgen receptors in sex steroid regulation of B lymphopoiesis. J. Immunol. 161:27-34.

2. Butterworth, M., McClellan, B., and Allansmith, M. 1967. Influence of sex in immunoglobulin levels. Nature. 214:1224-1225.

3. Schuurs, A.H., and Verheul, H.A. 1990. Effects of gender and sex steroids on the immune response. J. Steroid Biochem. 35:157-172.

4. Grossman, C.J., Roselle, G.A., and Mendenhall, C.L. 1991. Sex steroid regulation of autoimmunity. J. Steroid Biochem. Mol. Biol. 40:649-659.

5. Ansar, A.S., Penhale, W.J., and Talal, N. 1985. Sex hormones, immune responses, and autoimmune diseases. Mechanisms of sex hormone action. Am. J. Pathol. 121:531-551.

6. Whitacre, C.C. 2001. Sex differences in autoimmune disease. Nat Immunol. 2:777-780

7. Lahita, R.G., Bradlow, H.L., Kunkel, H.G., and Fishman, J. 1981. Increased 16 alpha-hydroxylation of estradiol in systemic lupus erythematosus. J. Clin. Endocrinol. Metab. 53:174-178.

8. Lahita, R.G., Bradlow, H.L., Kunkel, H.G., and Fishman, J. 1979. Alterations of estrogen metabolism in systemic lupus erythematosus. Arthritis Rheum. 22:1195-1198.

9. Strand, V. 1999. Biologic agents and innovative interventional approaches in the management of systemic lupus erythematosus. Curr. Opin. Rheumatol. 11:330-340.

10. Roubinian, J.R., Talal, N., Greenspan, J.S., Goodman, J.R., and Siiteri, P.K. 1978. Effect of castration and sex hormone treatment on survival, antinucleic acid antibodies, and glomerulonephritis in NZB/NZW F1 mice. J. Exp. Med. 147:1568-1583.

11. Roubinian, J., Talal, N., Siiteri, P.K., and Sadakian, J.A. 1979. Sex hormone modulation of autoimmunity in NZB/NZW mice. Arthritis Rheum. 22:1162-1169.

12. Carlsten, H., et al. 1992. Estrogen accelerates immune complex glomerulonephritis but ameliorates T cell-mediated vasculitis and sialadenitis in autoimmune MRL lpr/lpr mice. Cell Immunol. 144:190-202.

13. Verthelyi, D.I., and Ahmed, S.A. 1998. Estrogen increases the number of plasma cells and enhances their autoantibody production in nonautoimmune C57BL/6 mice. Cell Immunol. 189:125-134.

14. Bynoe, M.S., Grimaldi, C.M., and Diamond, B. 2000. Estrogen up-regulates Bcl-2 and blocks tolerance induction of naive B cells. Proc. Natl. Acad. Sci. USA. 97:2703-2708.

15. Peeva, E., Grimaldi, C., Spatz, L., and Diamond, B. 2000. Bromocriptine restores tolerance in estrogen-treated mice. J. Clin. Invest 106:1373-1379.

16. Grimaldi, C.M., Michael, D.J., and Diamond, B. 2001. Cutting edge: expansion and activation of a population of autoreactive marginal zone $\mathrm{B}$ cells in a model of estrogen-induced lupus. J. Immunol. 167:1886-1890.

17. Chirgwin, J.M., Przybyla, A.E., MacDonald, R.J., and Rutter, W.J. 1979. Isolation of biologically active ribonucleic acid from sources enriched in ribonuclease. Biochemistry. 18:5294-5299.

18. Hung, H.L., Song, F., and Gewirtz, A. 1999. A method for identifying differentially expressed genes in rare populations of primary human hematopoietic cells. Leukemia. 13:295-297.

19. Merino, R., Ding, L., Veis, D.J., Korsmeyer, S.J., and Nunez, G. 1994. Developmental regulation of the Bcl-2 protein and susceptibility to cell death in B lymphocytes. EMBO J. 13:683-691.

20. Sato, S., Tuscano, J.M., Inaoki, M., and Tedder, T.F. 1998. CD22 negatively and positively regulates signal transduction through the B lymphocyte antigen receptor. Semin. Immunol. 10:287-297.

21. Cyster, J.G., and Goodnow, C.C. 1995. Protein tyrosine phosphatase 1C negatively regulates antigen receptor signaling in B lymphocytes and determines thresholds for negative selection. Immunity. 2:13-24.

22. Strasser, A., et al. 1991. Enforced BCL2 expression in B-lymphoid cells prolongs antibody responses and elicits autoimmune disease. Proc. Natl. Acad. Sci. USA. 88:8661-8665.

23. Ryan, D.H., Nuccie, B.L., Abboud, C.N., and Winslow, J.M. 1991. Vascular cell adhesion molecule- 1 and the integrin VLA- 4 mediate adhesion of human B cell precursors to cultured bone marrow adherent cells. J. Clin. Invest. 88:995-1004.

24. Morel, L., Rudofsky, U.H., Longmate, J.A., Schiffenbauer, J., and Wakeland, E.K. 1994. Polygenic control of susceptibility to murine systemic lupus erythematosus. Immunity. 1:219-229.

25. Reuss-Borst, M.A., Ning, Y., Klein, G., and Muller, C.A. 1995. The vascular cell adhesion molecule (VCAM-1) is expressed on a subset of lymphoid and myeloid leukaemias. Br. J. Haematol. 89:299-305. 
26. Ishiyama, N., Kitagawa, M., Takahashi, H., Kina, T., and Hirokawa, K. 1998. Expression of VCAM-1 in lymphocytes during the process of apoptosis. Pathobiology. 66:274-283.

27. Smithson, G., Medina, K., Ponting, I., and Kincade, P.W. 1995. Estrogen suppresses stromal cell-dependent lymphopoiesis in culture. J. Immunol. 155:3409-3417.

28. Stimson, W.H. 1988. Oestrogen and human T lymphocytes: presence of specific receptors in the T-suppressor/cytotoxic subset. Scand. J. Immunol. 28:345-350.

29. Komi, J., and Lassila, O. 2000. Nonsteroidal anti-estrogens inhibit the functional differentiation of human monocyte-derived dendritic cells. Blood. 95:2875-2882.

30. Danel, L., et al. 1988. Estrogen and progesterone receptors in some human myeloma cell lines and murine hybridomas. J. Steroid Biochem. 30:363-367.

31. Suenaga, R., Evans, M.J., Mitamura, K., Rider, V., and Abdou, N.I. 1998. Peripheral blood $\mathrm{T}$ cells and monocytes and $\mathrm{B}$ cell lines derived from patients with lupus express estrogen receptor transcripts similar to those of normal cells. J. Rheumatol. 25:1305-1312.

32. Molina, J., et al. 1999. Differential effect of estradiol on antibody secretion of murine hybridomas. Hybridoma. 18:377-383.

33. Igarashi, H., Kouro, T., Yokota, T., Comp, P.C., and Kincade, P.W. 2001. Age and stage dependency of estrogen receptor expression by lymphocyte precursors. Proc. Natl. Acad. Sci. USA. 98:15131-15136.

34. Solum, D.T., and Handa, R.J. 2001. Localization of estrogen receptor alpha (ER alpha) in pyramidal neurons of the developing rat hippocampus. Brain Res. Dev. Brain Res. 128:165-175.

35. Nadler, M. J., McLean, P.A., Neel, B.G., and Wortis, H.H. 1997. B cell antigen receptor-evoked calcium influx is enhanced in CD22-deficient B cell lines. J. Immunol. 159:4233-4243.

36. Sandel, P.C., and Monroe, J.G. 1999. Negative selection of immature B cells by receptor editing or deletion is determined by site of antigen encounter. Immunity. 10:289-299.

37. Chen, W., Wang, H.G., Srinivasula, S.M., Alnemri, E.S., and Cooper, N.R 1999. B cell apoptosis triggered by antigen receptor ligation proceeds via a novel caspase-dependent pathway. J. Immunol. 163:2483-2491.

38. Sater, R.A., Sandel, P.C., and Monroe, J.G. 1998. B cell receptor-induced apoptosis in primary transitional murine $B$ cells: signaling requirements and modulation by $\mathrm{T}$ cell help. Int. Immunol. 10:1673-1682.

39. Cowley, S.M., and Parker, M.G. 1999. A comparison of transcriptional activation by ER alpha and ER beta. J. Steroid Biochem. Mol. Biol. 69:165-175

40. Cowley, S.M., Hoare, S., Mosselman, S., and Parker, M.G. 1997. Estrogen receptors alpha and beta form heterodimers on DNA. J. Biol. Chem. 272:19858-19862.

41. Patrone, C., et al. 2000. Estradiol induces differential neuronal phenotypes by activating estrogen receptor alpha or beta. Endocrinology. 141:1839-1845.

42. Wang, T.T., and Phang, J.M. 1995. Effects of estrogen on apoptotic pathways in human breast cancer cell line MCF-7. Cancer Res. 55:2487-2489.

43. Teixeira, C., Reed, J.C., and Pratt, M.A. 1995. Estrogen promotes chemotherapeutic drug resistance by a mechanism involving $\mathrm{Bcl}-2$ proto-oncogene expression in human breast cancer cells. Cancer Res. 55:3902-3907.

44. Perillo, B., Sasso, A., Abbondanza, C., and Palumbo, G. 2000. 17betaestradiol inhibits apoptosis in MCF-7 cells, inducing bcl-2 expression via two estrogen-responsive elements present in the coding sequence. $\mathrm{Mol}$. Cell Biol. 20:2890-2901.

45. Fulcher, D.A., and Basten, A. 1997. Influences on the lifespan of B cell subpopulations defined by different phenotypes. Eur. J. Immunol 27:1188-1199.

46. Hartley, S.B., et al. 1993. Elimination of self-reactive B lymphocytes proceeds in two stages: arrested development and cell death. Cell. 72:325-335.

47. Janani, R., et al. 1998. Effect of a bcl-2 transgene on production and localization of precursor B cells in mouse bone marrow. Exp. Hematol. 26:982-990.

48. Hande, S., Notidis, E., and Manser, T. 1998. Bcl-2 obstructs negative selection of autoreactive, hypermutated antibody $\mathrm{V}$ regions during memory B cell development. Immunity. 8:189-198.

49. Smith, K.G., et al. 2000. bcl-2 transgene expression inhibits apoptosis in the germinal center and reveals differences in the selection of memory B cells and bone marrow antibody-forming cells. J. Exp. Med. 191:475-484.

50. Medina, K.L., Strasser, A., and Kincade, P.W. 2000. Estrogen influences the differentiation, proliferation, and survival of early B-lineage precursors. Blood. 95:2059-2067.

51. Adachi, T., Flaswinkel, H., Yakura, H., Reth, M., and Tsubata, T. 1998. The B cell surface protein CD72 recruits the tyrosine phosphatase SHP-1 upon tyrosine phosphorylation. J. Immunol. 160:4662-4665.

52. O’Keefe, T.L., Williams, G.T., Batista, F.D., and Neuberger, M.S. 1999. Deficiency in CD22, a B cell-specific inhibitory receptor, is sufficient to predispose to development of high affinity autoantibodies. J. Exp. Med. 189:1307-1313.

53. Sidman, C.L., Shultz, L.D., Hardy, R.R., Hayakawa, K., and Herzenberg, L.A. 1986. Production of immunoglobulin isotypes by Ly-1+ $\mathrm{B}$ cells in viable motheaten and normal mice. Science. 232:1423-1425.

54. Hatta, Y., et al. 1999. Identification of the gene variations in human CD22. Immunogenetics. 49:280-286.

55. McMurray, R.W. 1996. Adhesion molecules in autoimmune disease. Semin. Arthritis Rheum. 25:215-233.

56. McHale, J.F., Harari, O.A., Marshall, D., and Haskard, D.O. 1999. TNFalpha and IL-1 sequentially induce endothelial ICAM-1 and VCAM-1 expression in MRL/lpr lupus-prone mice. J. Immunol. 163:3993-4000.

57. Koopman, G., et al. 1994. Adhesion through the LFA-1 (CD11a/CD18)ICAM-1 (CD54) and the VLA-4 (CD49d)-VCAM-1 (CD106) pathways prevents apoptosis of germinal center B cells. J. Immunol. 152:3760-3767.

58. Sato, S., Hasegawa, M., Fujimoto, M., Tedder, T.F., and Takehara, K. 2000. Quantitative genetic variation in CD19 expression correlates with autoimmunity. J. Immunol. 165:6635-6643.

59. Sato, S., Steeber, D.A., Jansen, P.J., and Tedder, T.F. 1997. CD19 expression levels regulate B lymphocyte development: human CD19 restores normal function in mice lacking endogenous CD19. J. Immunol. 158:4662-4669.

60. Kuo, P., Bynoe, M.S., Wang, C., and Diamond, B. 1999. Bcl-2 leads to expression of anti-DNA B cells but no nephritis: a model for a clinical subset. Eur. J. Immunol. 29:3168-3178. 